\title{
Efficient optimization of high vacuum chemical vapor deposition of niobium oxide on full wafer scale
}

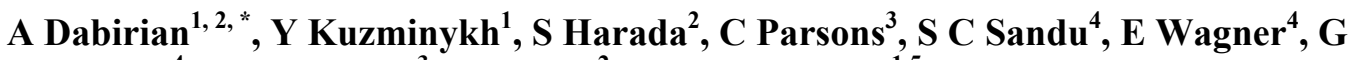 \\ Benvenuti $^{4}, S$ Rushworth ${ }^{3}$, $P$ Muralt ${ }^{2}$ and P Hoffmann ${ }^{1,5}$ \\ ${ }^{1}$ Institut de Microtechnique, Ecole Polytechnique Fédérale de Lausanne, Station 17, \\ CH-1015 Lausanne, Switzerland \\ ${ }^{2}$ Institut des Matériaux, Ecole Polytechnique Fédérale de Lausanne, Station 12, \\ CH-1015 Lausanne, Switzerland \\ ${ }^{3}$ SAFC Hitech Limited, Power Road, Bromborough, Wirral, UK CH62 3QF \\ 4 ABCD Technology Sarl, C/O UNIFID Conseils, 67 rue du Rhone, 1207 Genève, \\ Switzerland \\ 5 Swiss Federal Laboratories for Materials Testing and Research (EMPA), \\ Feuerwerkerstrasse 39, Thun CH-3602, Switzerland \\ Email: *ali.dabirian@epfl.ch
}

\begin{abstract}
A systematic study of niobium oxide deposition using niobium tetraethoxy-dimethylamino-ethoxide $\left(\mathrm{Nb}(\mathrm{OEt})_{4}(\mathrm{dmae})\right)$ precursor is presented. The deposition process was conducted in a high-vacuum chemical vapor deposition machine with precursor flux gradient capability. An efficient optimization of the deposition process was achieved and both mass-transport- and chemical-reaction-limited regimes were identified.
\end{abstract}

\section{Introduction}

Stoichiometric niobium (V) oxide [1] is a dielectric material with applications in photonics, photovoltaics, and capacitor applications. In addition to being used as an optical coating in photonics, niobium oxide is one of the precursors used to synthesize the compound lithium niobate $\left(\mathrm{LiNbO}_{3}\right)[1,2]$. Lithium niobate is an important material due to its electro-optical and low threshold nonlinear optical properties [2]. Recently niobium oxide has also been studied for applications in dye-sensitized solar cells [3], hybrid solar cells [4], and photo-catalytic hydrogen production from water [5].

Several methods have been used to prepare niobium oxide films such as sputtering [6], sol-gel method [7], atomic layer deposition [8], and chemical vapor deposition (CVD) [9]. Among these methods CVD is the one that is easily scaleable for mass production purposes. In CVD systematic study of new precursors is necessary to establish parameters for reproducible thin film deposition. This study is quite laborious and time-consuming because it necessitates conducting deposition experiments under different precursor flux and substrate temperatures since both influence the film properties.

Here we report on a new technique of high vacuum chemical vapor deposition (HV-CVD) that offers high deposition rate and easily up-scalable deposits of thin films of niobium oxide from $\mathrm{Nb}(\mathrm{OEt})_{4}(\mathrm{dmae})$ precursor. The precursor transport system in this novel tool allows spatial control of precursor impinging rate on the substrate. In one configuration flow gradients lead to analogous thickness gradients to allow, in a single experiment at a certain substrate temperature, the influence of different precursor flow rates to be studied. The conditions that lead to chemical reaction-limited or mass-transport-limited growth regimes for this precursor were identified using this technique. 


\section{Methods}

$\mathrm{Nb}(\mathrm{OEt})_{4}(\mathrm{dmae})$ was provided by SAFC Hitech. Proton NMR analysis of the isolated products showed no contamination from solvents and by products indicating achievement of greater than $99.9 \%$ purity. The precursor was continuously evaporated by uniformly heating the reservoirs without using carrier gas.

Thin films were deposited in a Sybilla-150 (ABCD Technology) high vacuum chemical vapor deposition reactor. The basic design and operating mode has been described previously [10] and modified to accommodate controlled-flow-gradient experiments. In this reactor the substrate is placed in a high-vacuum chamber in which a very low pressure (lower than $5 \times 10^{-5} \mathrm{mbar}$ ) prevent gas molecules to undergo any gas-phase collision with each other.

In this machine the precursors are delivered into the high vacuum chamber through prechambers. The geometrical design of the prechambers intentionally leads to a linear gradient of the impinging precursor flux on the substrate. The produced gradient across a $150 \mathrm{~mm}$ wafer is a ratio of three in the number of impinging precursor molecules, as predicted by mathematical models and Monte Carlo simulation. The model assumes that the precursor molecules evaporate as monomeric gas species. This assumption might not be the case for every precursor but it can be corrected with a linear correction factor determined by the mass loss of the precursor.

Thin films were deposited on $150 \mathrm{~mm}$ diameter naturally oxidized silicon (100) wafers. The cleanroom grade silicon wafers were used as received.

An evaporation temperature of $85^{\circ} \mathrm{C}$ (no carrier gas) was defined for $\mathrm{Nb}(\mathrm{OEt})_{4}(\mathrm{dmae})$. This leads to a precursor linear impinging rate gradient of $3.45 \times 10^{-12}$ to $1.4 \times 10^{-12} \mathrm{moles} /\left(\mathrm{mm}^{2} \mathrm{~s}\right)$ on the substrate. The systematic study of niobium oxide deposition was conducted at this precursor flux range and substrate temperatures of $320,345,367,410,460$, and $520^{\circ} \mathrm{C}$. Films were characterized by spectral reflectometry, spectral ellipsometry, X-ray photoelectron spectroscopy (XPS), scanning electron microscope (SEM) and X-ray diffraction (XRD). Spectral reflectometry and spectral ellipsometry were used for measuring the films thickness.

\section{Results and discussions}

The XPS analysis shows that the film deposited at $320^{\circ} \mathrm{C}$ was mostly composed of oxygen and carbon with small amount of niobium. This is a sign that $320^{\circ} \mathrm{C}$ is about the temperature at which the precursor just begins to decompose under the conditions employed. The deposited film at $345^{\circ} \mathrm{C}$ was shown by XPS to be predominantly niobium pentoxide with carbon contamination. The XRD analysis showed that this film was polycrystalline although it must be noted that niobium pentoxide at oxygen deficiencies up to $\mathrm{NbO}_{2.09}$ still show the X-ray diffraction lines that are characteristics of niobium pentoxide [1]. The film growth (deposition) rate was calculated by dividing the film thickness by duration deposition and was found to be homogenous all over the wafer at $220 \mathrm{~nm} / \mathrm{h}$. Since at this substrate temperature the growth rate is not influenced by the precursor flux it reveals that the deposition is in chemical-reactionlimited regime [11].

The growth rate of the niobium oxide thin films at various substrate temperatures is depicted in figure 1. Figure 1 (a) shows the films growth rate at $367^{\circ} \mathrm{C}$. As it can be seen at low precursor flux the growth rate is increasing with increasing precursor flux up to a certain point. Increasing the precursor flux beyond this flux tends to a decrease in the growth rate (the range marked with a blue band). We conclude that at low precursor flux the deposition is in the mass-transport-limited regime while in the part that the growth rate is decreasing with increasing the precursor flux is in the transition from mass-transportlimited regime to chemical-reaction-limited regime [11]. Apart from the highest flux part at $410{ }^{\circ} \mathrm{C}$ substrate temperature, highlighted with a blue band on the graph, which shows growth rate saturation due to being in the transition regime, the other deposition conditions yield a linear increase in growth rate with increasing precursor flux to reveal that the deposition is in the mass-transport-limited regime. 
The XPS analysis shows that in the transition and the mass transport-limit regimes the films are solely oxygen deficient niobium pentoxides with no carbon contamination detectable using this technique. The XRD analysis shows that the films are polycrystalline niobium pentoxide.

(a)

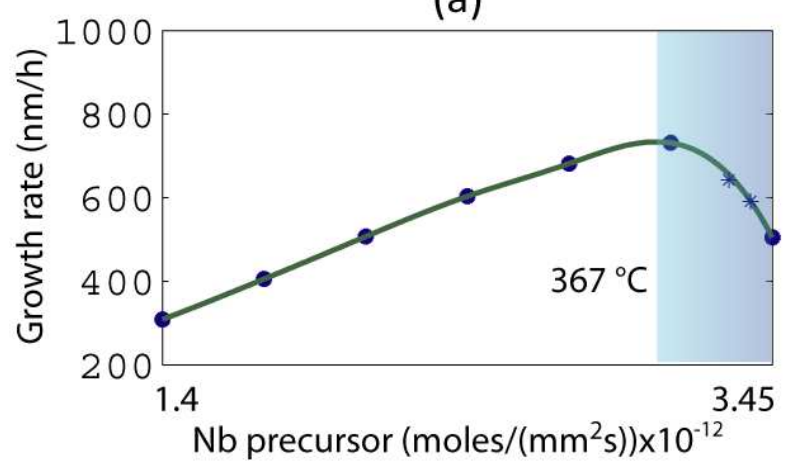

(c)

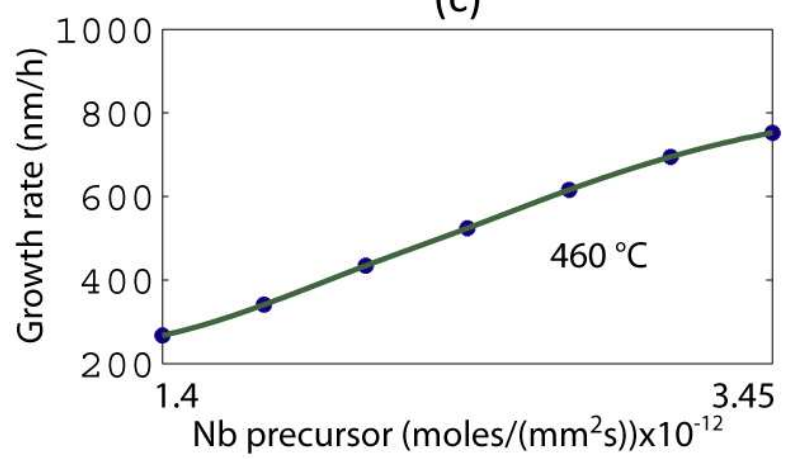

(b)

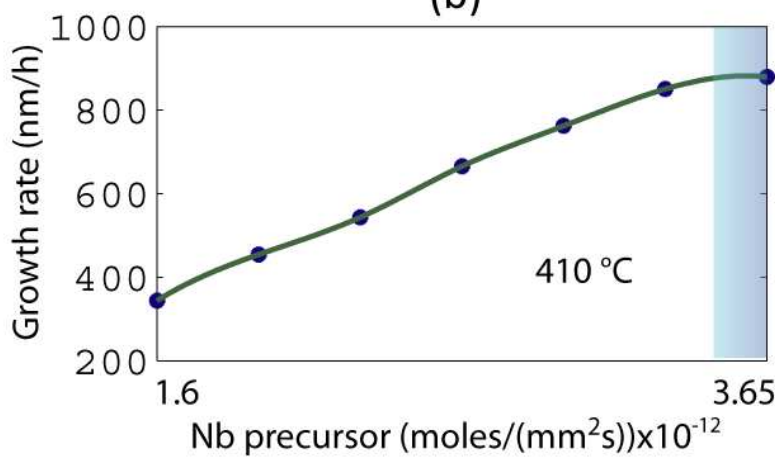

(d)

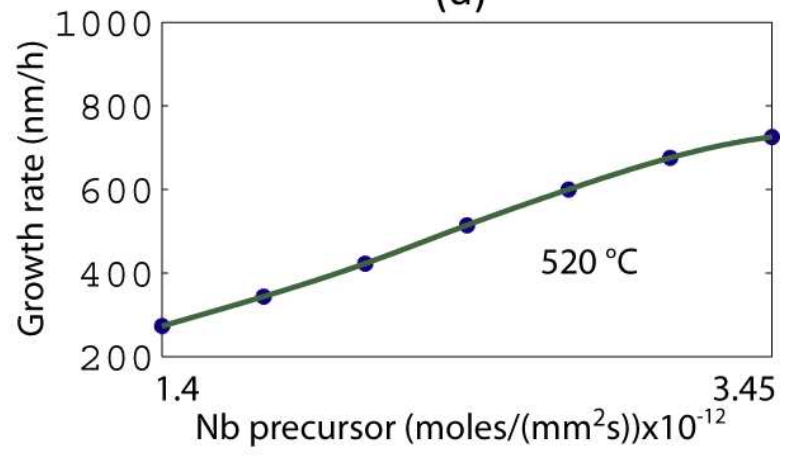

Figure 1. The growth rate of the niobium oxide films deposited on silicon at substrate temperature ( $\mathrm{T}_{\text {sub }}$ ) (a) $367^{\circ} \mathrm{C}$, (b) $410^{\circ} \mathrm{C}$, (c) $460^{\circ} \mathrm{C}$, and (d) $520^{\circ} \mathrm{C}$. The blue bands on the graph stand for the flux ranges at which the deposition is in transition regime. At the rest it is in mass-transport-limited regime.

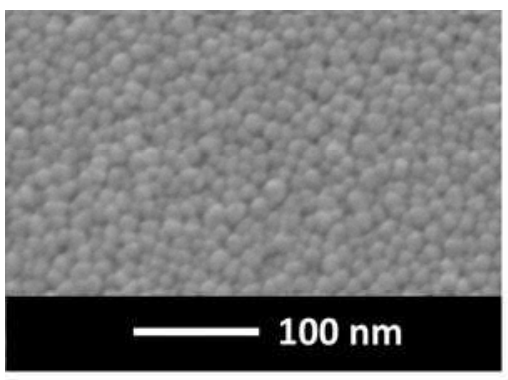

(a)

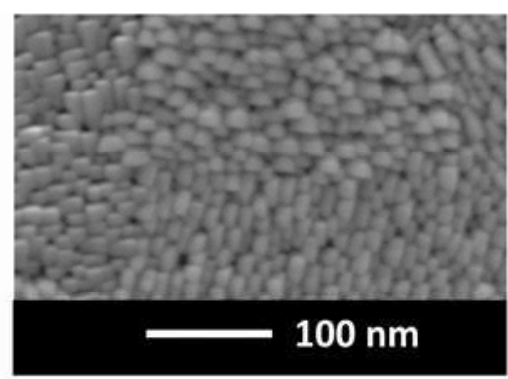

(b)

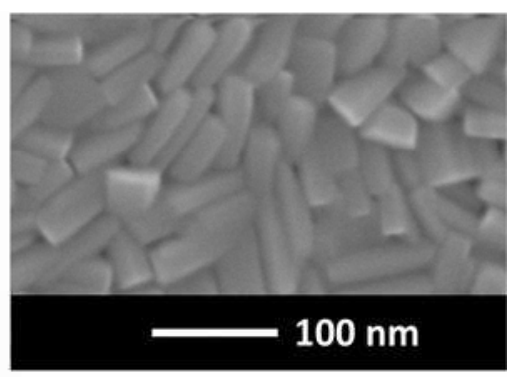

(c)

Figure 2. SEM images of niobium oxide films grown on silicon at (a) $345^{\circ} \mathrm{C}$, (b) $410^{\circ} \mathrm{C}$, and (c) $520^{\circ} \mathrm{C}$.

The surface morphology of the film investigated in SEM is depicted in figure 2. The films exhibit a surface structure consisting of grains with different size and morphology. The film deposited at $345^{\circ} \mathrm{C}$ is composed of small grains (figure 2 (a)). The surface morphology of the film deposited at $410^{\circ} \mathrm{C}$ (in the low precursor flux part) shows sharper grain corners and a slight increase in size of the grains. The deposited film at $520^{\circ} \mathrm{C}$ shows a surface morphology with well-faceted grains and sizes as big as $100 \mathrm{~nm}$ 
(figure $2(\mathrm{c})$ ). It must be noted that in mass-transport-limited regime no significant change in surface morphology was observed in SEM.

\section{Conclusions}

Precursor flux gradient capability that is integrated in a HV-CVD machine proves to be an efficient technique for systematic study and optimization of niobium oxide films deposited from $\mathrm{Nb}(\mathrm{OEt})_{4}(\mathrm{dmae})$. Substrate temperature and precursor flux ranges leading to chemical-reaction- or mass-transport-limited deposition regimes were identified.

\section{Acknowledgements}

The authors would like to thank Nicolas Xanthopoulos for XPS measurements and the E.U. for funding via the 3D - DEMO (STREP 033297) project.

\section{References}

[1] Nowak I and Ziolek M 1999 Chem. Rev. 993603.

[2] Weis R S and Gaylord T K 1985 Appl. Phys. A-Materials Science \& Processing 37191.

[3] Jose R, Thavasi V and Ramakrishna S 2009 J. Am. Ceram. Soc. 92289.

[4] Lira-Cantu M, Norrman K, Andreasen J W and Krebs F C 2006 Chem. Mater. 185684.

[5] Maeda K, Eguchi M, Youngblood W J and Mallouk T E 2008 Chem. Mater. 206770.

[6] Lai F, Li M, Chen K, Wang H, Song A and Jiang Y 2005 Appl. Opt. 446181.

[7] Avellaneda c O, Pawlicka A and Aegerter M A 1998 J. Mater. Sci. 332181.

[8] Kukli K, Ritala M, Leskela M and Lappalainen R 1998 Chem. Vap. Deposition 429.

[9] O'Neill S A, Parkin I P, Clark r J H, Mills A and Elliott N 2003 J. Mater. Chem. 132952.

[10] Benvenuti G, Halary-Wagner E, Brioude A and Hoffmann P 2003 Thin Solid Films 427411.

[11] Choy K L 2003 Progr. Mater. Sci. 4857. 